\title{
Taxi drivers' exceptional memory of street names
}

\author{
VIRPI KALAKOSKI and PERTTI SAARILUOMA \\ University of Helsinki, Helsinki, Finland
}

\begin{abstract}
In this paper, we explore the nature of taxi drivers' serial recall of street names. The main question is whether the memory of verbal material benefits from the possibility of using visuospatial associations and knowledge concerning large-scale environment. In two experiments, expert taxi drivers' recall of street names was superior to that of control groups. In Experiment 1, experts' superiority of memory was greater when the street names reflected a visuospatially continuous route than when the street names were located along a straight line across the map without spatial continuity or were presented in random order. In Experiment 2, the expert taxi drivers recalled spatially continuously organized lists much better than they recalled lists of street names belonging to the same semantic category or lists presented in alphabetical order. This result also suggests that interitem associations, which are based on spatial co-occurrence, are efficient in comparison with other mnemonics.
\end{abstract}

It is sufficiently well demonstrated that experts are exceptional in remembering information in their skillspecific task environment, and that their performance exceeds all the limits of short-term or working memory capacity (Ericsson \& Kintsch, 1995). Thus, a digit-span expert is able to recall digit lists consisting of more than 80 digits (Chase \& Ericsson, 1981), an experienced waiter is able to take up to 20 dinner orders without taking notes (Ericsson \& Polson, 1988), and an expert chess player can recall 20-24 of 25 pieces presented for $5 \mathrm{sec}$ on a chessboard (de Groot, 1965, 1966).

A general interpretation of expertise effects in memory tasks is that experts are able to surpass short-term or working memory capacity limitations because they have vast prelearned task-specific long-term memory knowledge with which they can encode stimulus information into large chunks (Charness, 1976; Chase \& Ericsson, 1982; Chase \& Simon, 1973; Ericsson \& Kintsch, 1995). Though the empirical phenomenon is generally accepted, there are competing theoretical explanations postulating somewhat different underlying mechanisms. The most important of them have been long-term working memory (Ericsson \& Kintsch, 1995), template theory (Gobet \& Simon, 1996), and the constraint attunement hypothesis (Vicente \& Wang, 1998).

The first two theories provide a psychological explanation for expertise effects in memory tasks by supposing that experts overcome short-term/working memory limitations by using prelearned retrieval structures or templates to encode, store, and recall incoming information rapidly (Chase \& Ericsson, 1981; Ericsson \& Kintsch,

This research was supported by The Academy of Finland and the Anna S. Elonen Foundation. We thank K. Anders Ericsson, Kim Vicente, and two anonymous reviewers for their valuable comments on an earlier version of this article. Correspondence should be addressed to V. Kalakoski, Department of Psychology, P.O. Box 13, 00014 University of Helsinki, Finland (e-mail: virpi.kalakoski@helsinki.fi).
1995; Gobet \& Simon, 1996; Richman, Staszewski, \& Simon, 1995). The third, the constraint attunement hypothesis, is based on an ecological approach and suggests that the expertise advantage in memory performance is affected by the number of goal-relevant constraints available, and it also depends on whether experts are attuned to these constraints (Vicente \& Wang, 1998). Consequently, there are some theoretical controversies over the explanations that these theories offer regarding existing data (Ericsson, Patel, \& Kintsch, 2000; Simon \& Gobet, 2000; Vicente, 2000).

The main discriminative characteristic of skilled memory experiments that makes them different from standard memory experiments is expertise and domain specificity (Chase \& Ericsson, 1981; Ericsson \& Kintsch, 1995). For this reason, we are interested in taxi drivers' memory of street names. Previous research in this domain has shown that expert taxi drivers can, for example, name more streets than novices, and that they are far more skilled at generating driving routes (Chase, 1983). Furthermore, locations in the city seem to be hierarchically organized in expert taxi drivers' memories, and they can efficiently use perceptual knowledge to trigger known routes associated with these visual cues (Chase, 1983).

We suggest that it might be possible to use taxi drivers also to investigate whether knowledge concerning largescale visuospatial environment affects immediate serial verbal recall. Consequently, this task offers a new environment for studying the role of visuospatial encoding in the cooperation between short-term working memory and long-term memory, an important current research issue (e.g., Baddeley, 2000; Hishitani, 1989; Logie, 1995; Marschark \& Surian, 1992; Robbins et al., 1996; Saariluoma, 1991, 1995; Saariluoma \& Kalakoski, 1997, 1998).

In order to study whether taxi driver's serial verbal recall is based on visuospatial encoding of the items, we chose a method of manipulating the organization of the items in a list. In Experiment 1, we manipulated the level 
of task-relevant spatial information available by presenting lists consisting of street names of Helsinki in route, map, or randomized order. In Experiment 2, we also studied whether expert taxi drivers are able to use mnemonics that are not based on domain-relevant spatial coding but on alphabetical order or semantic categorization.

\section{EXPERIMENT 1}

We studied the role of prelearned knowledge in recalling street names by comparing expert taxi drivers' and control participants' recall of Helsinki street names. We hypothesized that this task would provide a new example of skilled memory in a contrived task, and that we should find a clear skill effect on recall.

Furthermore, we presented lists of Helsinki street names by using four degrees of spatial randomness. First, we presented successive street names that formed a spatially continuous route through part of the city (route order). Second, these spatially continuous lists of street names were also presented in random order, and thus they did not include any spatially continuous route (route random). Third, we used street names that formed a straight line through the Helsinki city map. Because many intermediate streets were omitted, the series did not form spatially continuous and, in this sense, realistic lists of street names (map order). Fourth, we presented map-order streets in random order (map random).

We hypothesized that taxi drivers would recall more streets in the route order condition that in the other conditions, because route order reflects task-relevant spatial information-streets in successive order-better than the other conditions. Furthermore, we supposed that in the map order condition, taxi drivers would recall more street names than in the map-randomized condition, because map order still reflects to some degree spatially realistic information-as in the case of subroutes between two distant locations, for example.

\section{Method}

Participants. Eight taxi drivers with 3-7 years of experience of full-time taxi driving in the Helsinki city area and 8 students from Helsinki University participated in this study. They were paid for their participation.

Procedure. Twelve series of 15 street names were read onto a tape at a speed of 1 street per $5 \mathrm{sec}$. In 6 lists every alternate street formed a spatially continuous route through part of the city, but half of these lists were presented in random order. ${ }^{1}$ In 6 lists the alternate streets formed a straight line across the Helsinki city map, but half of these lists were presented in random order. After presentation of each list, participants were asked to recall as many items from the list as possible, in perfect serial order, beginning from the first item. At the end, they were allowed to mention also the streets whose serial order they were not able to recall. The time limit for the recall was $1 \mathrm{~min} /$ list. The order of presentation of the four types of lists and the randomization of alternate streets were counterbalanced between the participants.

\section{Results}

Results concerning the number of items correctly recalled from the list in any order are presented in Figure 1.

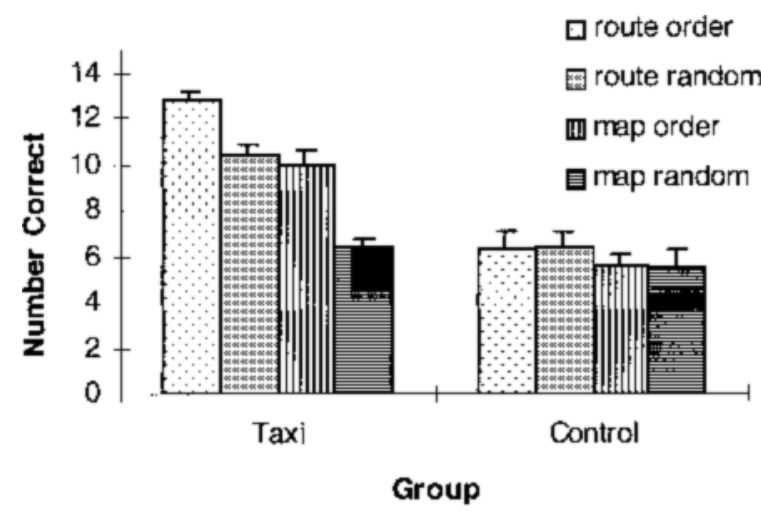

Figure 1. Number of street names recalled correctly in any order by skill level (taxi drivers vs. control participants) and list type (route order vs. route random vs. map order vs. map random).

A two-way analysis of variance (ANOVA) was used to study the effects of skill level (between subjects) and degree of randomness (within subjects) on the number of correctly recalled street names. Besides main effects and the interaction between skill level and degree of randomness, we were also interested in certain specific differences. Thus, detailed comparisons of relevant means were conducted with $t$ tests in which familywise error rate was controlled with Bonferroni correction, and each of the individual contrasts was tested at the level of .05/number of contrasts to be tested (Howell, 1997, pp. 362-369).

A two-way ANOVA showed that the interaction between skill level and degree of randomness was significant $[F(3,42)=15.52, p<.001]$, as were these main effects $[F(1,14)=32.34, p<.001$, and $F(3,42)=25.97$, $p<.001$, respectively]. Bonferroni $t$ tests at the level of $p<.003$ showed that experts recalled more items than did the control group in three of the four conditions: route order, route random, and map order lists $[t(14)=$ $7.31, t(14)=4.62, t(14)=5.27$, respectively]

Furthermore, when the four conditions in the experts' group were compared, it was found that they recalled more items from route order lists than from route random or map order lists $[t(7)=7.80, t(7)=4.90$, respectively $]$. Moreover, experts recalled fewer items from the map random lists than from the other list types $[t(7)=17.63$ for route order, $t(7)=11.24$ for route random, and $t(7)=$ 4.53 for map-order lists]. In the control group, there was no statistically significant difference among the four conditions.

\section{Discussion}

The experts' superior recall in comparison with the novices' recall in the route order, route random, and map order conditions supports the hypothesis that experts are able to use prelearned knowledge concerning a large-scale visuospatial environment in the verbal street memory task. Thus, this is a new example of expertise advantage in a contrived memory task that is not a normal task in the domain but rather a by-product of the special skillin this context, skill in driving a taxi in a particular city. 
Furthermore, expert taxi drivers' recall was higher in the spatially well-organized route order condition than in the route random condition, and also higher in the map order condition than in the map random condition. Moreover, the recall level was higher in the route conditions than in the map conditions. This effect of spatial organization suggests that taxi drivers' exceptional memory of street names is based on prelearned knowledge that enables them to use spatial chunking in order to overcome short-term/working memory capacity limitations. The experts' introspective comments also suggest that they were using their route knowledge during the memory task by trying to mentally simulate driving a route.

\section{EXPERIMENT 2}

Although the results of the first experiment were logical, they did not rule out the possibility that other kinds of mnemonics would be as efficient as spatial organization. In order to study this hypothesis, we used two new kinds of lists besides route and random lists. First, we constructed lists of real street names in alphabetical order to study the effect of alphabets as a memory cue. Second, we used more semantic organization by choosing real street names that belonged to the same category: names that were related to the sea, to plants, and to animals. These types of manipulations were selected because it is well known that people use such regularities in chunking stimulus information in list-learning experiments (Marschark \& Surian, 1992). The crucial question was whether the possibility of using alphabetic or semantic chunking would be as effective as spatial chunking.

\section{Method}

Participants. The same 8 taxi drivers with 3-7 years of experience of full-time taxi driving in the Helsinki city area and the same 8 students from Helsinki University participated as in Experiment 1. They were paid for their participation.

Procedure. Lists consisting of 15 names of real Helsinki streets were read onto a tape as in the previous experiment. There were four types of lists. First, in three lists the 15 street names belonged to the same category. One list consisted of names related to the sea (e.g., Oar Street, Anchor Avenue, Keel Street), another contained plants (e.g., Lilac Street, Pine Street, Ivy Avenue), and the third concerned animals (e.g., Swan Street, Hedgehog Avenue, Reindeer Street). This was the semantic condition. Second, in three lists the street names were given in alphabetical order (alphabetic condition). The third type of list consisted of three lists of streets that formed a continuous route in the city (route order). Fourth were three lists consisting of streets that formed a route but were organized in random order (route random).

After presentation of every list, the participants had at the most $1 \mathrm{~min}$ to recall the street names in perfect order from the beginning. The order of presentation of each condition was randomized, and the series of street names used in spatial and random condition was counter-balanced between participants.

\section{Results}

The effects of skill level (taxi drivers vs. control) and organization (categorical, alphabetical, route, random) was tested in a two-way ANOVA. The results concerning

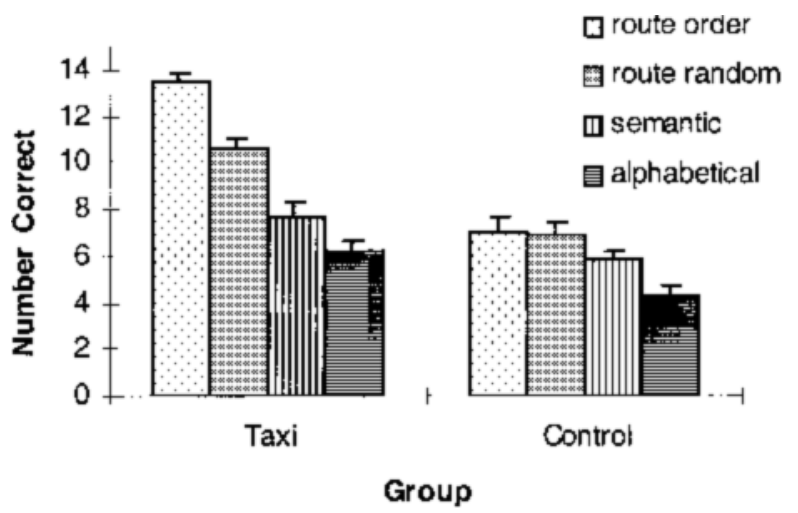

Figure 2. Number of street names recalled correctly in any order by skill level (taxi drivers vs. control participants) and list type (route order vs. route random vs. semantic vs. alphabetical).

overall recall are presented in Figure 2. The ANOVA showed that the two-way interaction between skill level and organization was significant $[F(3,42)=14.77, p<$ $.001]$, as were the main effects of skill level $[F(1,14)=$ $48.88, p<.001]$ and organization $[F(3,42)=56.64, p<$ $.001]$. Planned comparisons at the level of $p<.003$ showed that taxi drivers recalled more items than did the control group in the route order and route random conditions $[t(14)=8.58, t(14)=4.95$, respectively]. However, there was no skill difference in the semantic and alphabetical conditions.

Furthermore, in the expert group the difference in recall of alphabetical and semantic lists was not statistically quite significant, but all other differences between the means were significant at the level of $p<.003$, with all $t$ values between 4.84 and 23.39. In the control group, the fewest number of items were recalled from the alphabetical lists, which differed significantly from the recall of route order lists $[t(7)=4.34, p=.003]$.

\section{Discussion}

The recall scores show that the skill difference in recall applied only to route lists presented in route and random order. Moreover, taxi drivers recalled route-organized lists, even when these were presented in random order, better than semantically or alphabetically ordered lists; but in the control group there was no difference in recall among route-organized, random, and semantically classified lists. This finding clearly supports our hypothesis that taxi drivers are able to use domain-specific or ecologically relevant information in this constraint memory task (Ericsson et al., 2000; Vicente \& Wang, 1998).

It is evident that semantic and alphabetical organization are not in line with task constraints that taxi drivers face when they generate the best routes that they can and drive between locations in the city. Although semantic relations between items are a good mnemonic for verbal material, they are not essential to taxi drivers' skilled serial memory of street names, because the taxi-driver's expertise-specific spatial mnemonic is efficient. 


\section{GENERAL DISCUSSION}

In this paper, we have shown new evidence for skilled memory as a contrived task. Our experiments show that taxi driving experts are superior to novices in memorizing lists of street names. In this case, prelearned knowledge concerning a large-scale spatial environment, the city, is used in memorizing verbal material. This result is consistent with earlier research concerning skilled memory (Charness, 1976; Chase \& Ericsson, 1981; Ericsson $\&$ Kintsch, 1995). Furthermore, the results also give additional information about the mechanism of using meaningful visuospatial knowledge in long-term memory in order to increase immediate verbal recall.

The skill difference was true for the recall of lists consisting of familiar streets presented in route order, route random, and map order. However, there was no skill difference for the recall of lists presented in alphabetical order, nor for street names belonging to the same semantic category, as was shown in Experiment 2. Our results suggest that taxi drivers' exceptional recall of street names is based on associating individual items with a spatial structure corresponding to the task environment. However, the effect of list organization suggests that only associating verbal street labels with the locations on the map does not guarantee superior memory in this task unless the items constitute a spatially logical path. Only spatial relations between the items, not semantic or alphabetical mnemonics, are crucial.

Could one also explain these results without assuming a visuospatial representation? It has been shown, for example, that memory span is related to word frequency (Hulme, Maughan, \& Brown, 1991), and the skill effect in our experiments could only indicate the fact that street names occur more often in the lives of taxi drivers than in those of other people. Moreover, it has been shown that short-term memory span is sensitive to the frequency of co-occurrence of adjacent items. Stuart and Hulme (2000) repeatedly presented their subjects with word pairs in order to increase the strength of interitem associative links in long-term memory before giving a serial recall task. Their results showed that familiarizations with pairs of words improved serial recall of low-frequency words to the level for high-frequency words. This result indicates that interitem associations in long-term memory affect short-term memory performance (Stuart \& Hulme, 2000). Undoubtedly, a somewhat similar associative learning mechanism may be involved when taxi drivers gradually learn the locations of the streets in a city. However, in the taxi driving domain, the interitem associations are of a specific kind; they are based on spatial closure of the items.

Interestingly, the relational coding of individual items is also considered to be one of the mechanisms underlying the effectiveness of a mental imagery mnemonic in memory recall (Marschark \& Surian, 1989, 1992). Moreover, the important role of relational coding of visuospatial items is evident in the research into experts' images (Hatta, Hirose, Ikeda, \& Fukuhara, 1989; Hishitani,
1989, 1990; Saariluoma, 1992; Saariluoma \& Kalakoski, 1997; Stigler, 1984). For example, soroban experts are able to use a mental abacus in order to remember digit lists (Hatano \& Osawa, 1983), and chess players are able to play, blindfolded-that is, without seeing a board and pieces-as many as 10 games simultaneously (Saariluoma, 1991). It is obvious that only skilled people are able to chunk domain-relevant information, and that they can thus construct visual and spatial images that require a capacity surpassing the limits of visuospatial working memory (Saariluoma, 1991; Saariluoma \& Kalakoski, 1997).

To sum up, our research offers a new task environment for studying expertise effects in memory recall in a contrived task. Our findings imply that in some expert groups the psychological mechanism underlying the welldemonstrated phenomenon of exceptional memory is relational encoding based on spatial associations. This has important implications for two topics. First, our research concerns the still understudied puzzle regarding the specific psychological mechanisms underlying expertise effects in memory recall, and thus it can clarify the theories concerning expertise effects in memory recall. Second, our results contribute a more detailed explanation of the role of visuospatial representations in the cooperation between short-term memory and long-term memorythat is, skilled imagery.

\section{REFERENCES}

BAdDeley, A. (2000). The episodic buffer: A new component of working memory? Trends in Cognitive Sciences, 4, 417-423.

Charness, N. (1976). Memory for chess positions: Resistance to interference. Journal of Experimental Psychology: Human Learning \& Memory, 2, 641-653.

Chase, W. G. (1983). Spatial representations of taxi drivers. In D. A. Rogers \& J. A. Sloboda (Eds.), The acquisition of symbolic skills (pp. 391-405). New York: Plenum.

Chase, W. G., \& Ericsson, K. A. (1981). Skilled Memory. In J. R. Anderson (Ed.), Cognitive skills and their acquisition (pp. 141-189). Hillsdale, NJ: Erlbaum.

Chase, W. G., \& ERICsson, K. A. (1982). Skill and working memory. In G. H. Bower (Ed.), The psychology of learning and motivation (Vol. 16, pp. 1-58). New York: Academic Press.

Chase, W. G., \& Simon, H. A. (1973). The mind's eye in chess. In W. G. Chase (Ed.), Visual information processing (pp. 215-281). New York: Academic Press.

DE Groot, A. D. (1965). Thought and choice in chess. The Hague: Mouton.

DE Groot, A. D. (1966). Perception and memory versus thought: Some old ideas and recent findings. In B. Kleinmuntz (Ed.), Problem solving (pp. 19-50). New York: Wiley.

ERICSSON, K. A., \& KinTSCH, W. (1995). Long-term working memory. Psychological Review, 102, 211-245.

Ericsson, K. A., Patel, V., \& Kintsch, W. (2000). How experts' adaptations to representative task demands account for the expertise effect in memory recall: Comments on Vicente and Wang (1998). Psychological Review, 107, 578-592.

ERICsSOn, K. A., \& Polson, P. G. (1988). A cognitive analysis of exceptional memory for restaurant orders. In M. T. H. Chi, R. Glaser, \& M. J. Farr (Eds.), The nature of expertise (pp. 23-70). Hillsdale, NJ: Erlbaum.

Gobet, F., \& Simon, H. A. (1996). Templates in chess memory: A mechanism for recalling several boards. Cognitive Psychology, 31, 1-40.

Hatano, G., \& Osawa, K. (1983). Digit memory of grand experts in abacus-derived mental calculation. Cognition, 15, 95-110. 
Hatta, T., Hirose, T., Ikeda, K., \& Fukuhara, H. (1989). Digit memory of soroban experts: Evidence of utilization of mental imagery. Applied Cognitive Psychology, 3, 23-33.

Hishitani, S. (1989). The usefulness of studies of imagery experts in imagery research. Journal of Mental Imagery, 13, 119-134.

Hishitani, S. (1990). Imagery experts: How do expert abacus operators process imagery? Applied Cognitive Psychology, 4, 33-46.

Howell, D. C. (1997). Statistical methods for psychology (4th ed.). Belmont, CA: Duxbury Press.

Hulme, C., Maughan, S., \& Brown, G. D. A. (1991). Memory for familiar and unfamiliar words: Evidence for a long-term memory contribution to short-term memory span. Journal of Memory \& Language, 30, 685-701.

LogIE, R. H. (1995). Visuo-spatialworking memory. Hove, U.K.: Erlbaum.

MARSCHARK, M., \& SURIAN, L. (1989). Why does imagery improve memory? European Journal of Cognitive Psychology, 1, 251-263.

MarSChark, M., \& Surian, L. (1992). Concreteness effects in free recall: The roles of imaginal and relational processing. Memory \& Cognition, 20, 612-620.

Richman, H. B., Staszewski, J. J., \& Simon, H. A. (1995). Simulation of expert memory with EPAM IV. Psychological Review, 102, 305-330.

Robbins, T. W., Anderson, E. J., Barker, D. R., Bradley, A. C., Fearnyhough, C., Henson, R., Hudson, S. R., \& Baddeley, A. D. (1996). Working memory in chess. Memory \& Cognition, 24, 83-93.

SAARILUOMA, P. (1991). Aspects of skilled imagery in blindfold chess. Acta Psychologica, 77, 65-89.

SAARILUOMA, P. (1992). Visuo-spatial and articulatory interference in chess players' information intake. Applied Cognitive Psychology, $\mathbf{6}$, 77-89.

SAARILUOMA, P. (1995). Chess players' thinking. London: Routledge.

SAARILUOMA,P., \& KALAKOSKI, V. (1997). Skilled imagery and long-term working memory. American Journal of Psychology, 110, 177-201.
SAARILUOMa, P., \& KAlaKoski, V. (1998). Apperception and imagery in blindfold chess. Memory, 6, 67-90.

Simon, H. A., \& Gobet, F. (2000). Expertise effects in memory recall: Comments on Vicente and Wang 1998. Psychological Review, 107, 593-600.

Stigler, J. W. (1984). "Mental abacus": The effect of abacus training on Chinese children's mental calculation. Cognitive Psychology, 16, 145-176.

Stuart, G., \& Hulme, C. (2000). The effects of word co-occurrence on short-term memory: Associative links in long-term memory affect short-term memory performance. Journal of Experimental Psychology: Learning, Memory, \& Cognition, 26, 796-802.

VICENTE, K. J. (2000). Revisiting the constraint attunement hypothesis: Reply to Ericsson, Patel, and Kintsch (2000) and Simon and Gobet (2000). Psychological Review, 107, 601-608.

Vicente, K. J., \& WANG, J. H. (1998). An ecological theory of expertise effects in memory recall. Psychological Review, 105, 33-57.

\section{NOTE}

1. We manipulated the spatial contiguity of the routes, which the lists of street names reflect, not the drivability of the routes. The lists consisting of spatially continuous routes in our experiments were drivable only in the sense that the presented streets were spatially successive. However, they were not drivable in the sense that all the traffic rules could be followed. For example, whether the route was one-way and could be driven in that direction, or whether the street was actually closed because of repairs, for example, affected the drivability of the routes.

(Manuscript received October 26, 1998; revision accepted for publication January 28, 2001.) 